\title{
COMPUTING URBAN MOBILE LANDSCAPES THROUGH MONITORING POPULATION DENSITY BASED ON CELL-PHONE CHATTING
}

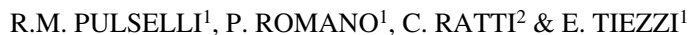 \\ ${ }^{1}$ Department of Chemical and Biosystems Sciences, University of Siena, Siena, Italy. \\ ${ }^{2}$ SENSEable City Laboratory, Massachusetts Institute of Technology (MIT), Cambridge, MA, USA.
}

\begin{abstract}
This study conducts traffic data of mobile-phone antennas, recorded by a telecommunications company, to develop a real-time monitoring technique of population density in an urban area, given that the intensity of activity in a cell (a covered area around an antenna) is directly proportional to the presence of cell-phone users. An application of this technique to the metropolitan area of Milan (Italy) is presented. Results are illustrated in the form of patch dynamics through a sequence of maps showing how people use urban space in time (e.g. monitoring 24 hours of a working day; comparing working days with Saturday and Sunday; observing special events such as a soccer match at the stadium). In other words, the method presented allows for the visualization of social dynamics in a built-up environment and may provide a spatial zoning based on time use of urban functions. This relates to a human ecosystem framework that provides a theoretical approach to investigate how urban structures affect the distribution of organisms (people), integrating spatial and temporal aspects. Once tested, potential practical applications of this technique were discussed to improve the efficiency of urban systems management and planning through the monitoring of their dynamics.
\end{abstract}

Keywords: cell-phones, landscape ecology, location based services, macro-organization, mobile geographies, monitoring technique, social patterns, telecommunications technology, urban systems.

\section{INTRODUCTION}

New telecommunications technology has changed our ways of exchanging information, interacting, moving, and using urban space, both public and private. This transformation of social behaviour has made our perceptions of a city change as well, as complexity has increased and interactions among individuals in the built-up environment have grown. Technology for mobile telecommunications, in particular, has made some procedures easier, and activities that once needed a fixed position may now enjoy a wireless web connectivity. On one hand, this enhanced freedom has made the use of urban space more flexible, even maintaining full wireless connectivity and traceableness; on the other hand, this has made it more complicated to know and understand. Nevertheless, this technology can be a valuable source of information for the study of social dynamics and their interactions with the urban structural frame, as we will be demonstrating in this paper.

New technology, namely location-based services [1,2], has been developed since 1995, initially for emergency issues, and then for providing services to individual cell phone users (e.g. navigational aids/tools, interactivity with the physical environment, interactivity with other users). A detailed overview of these services is available in the cited literature [3]. This technology was recently implemented for the monitoring of social systems as a whole, as well as for the Social Positioning Method that studies social flows in time and space by analysing the location coordinates of mobile phones [3-8].

Data recorded by mobile telecommunications antennas can be computed for monitoring the intensity of traffic and, approximately, the density of people in urban areas, as we may assume that cell-phone activity (when people are chatting) is proportional to the presence of mobile-phone users; statistics on mobile telecommunications [9] in Italy show that the number of cell-phones is almost equivalent to the population (54 million cell phones per 58 million people, including children and 
the elderly - almost one phone per person). Therefore, based on this data, density maps, hotspots surfaces and patch dynamics can be generated for understanding cities, even considering that contemporary city is not rendered through composition, gravity, form, or material, as much as it is through demographics, social and economic performance, as Koolhaas et al. [10] stated, and added: no longer is the city visualized or composed as much as it is empirically computed.

In particular, this paper develops a technique for monitoring social activity in a built-up environment and its evolution over time. Time series data were executed to investigate the time mode of urban space use. With respect to other traditional analyses such as, for example, those based on functional zoning, that show 'how' different urban space is used, this analysis shows 'when' and 'how long' urban space is used.

The description of these aspects through the elaboration of time-space parameters, in this study, has revealed variable configurations given by the activity of a community of organisms (people) in a built-up environment. This configuration is a tangible expression of an urban social system organization and its mode of functioning: it constitutes a variable, multiple and periodically changeable landscape. This refers to a human ecosystem framework that brings ecological understanding to bear in metropolitan systems [11, 12]. As a theoretical approach, it suggests factors and phenomena to investigate that combine structure and function of metropolitan ecosystems. This is intended as the study of how urban structures affect the abundance and distribution of organisms. The effect of pattern on process $[13,14]$, with 'pattern' here referring specifically to landscape structure, is investigated. At least, this would be also an attempt to offer a methodological step that may be instrumental in investigating the functioning of the mechanisms that dominate the flow of material exchanges (e.g. life of a city, community, society at large) and for revealing the processes constituting 'place-ness' today [15].

There are numerous potential practical applications of this technique for monitoring urban-social systems when implemented into the whole infrastructure network, especially by virtue of the capacity to visualize the comprehensive behaviour of the entire urban system and its organization at a glance. This would inform urban management and planning practices considering that, for every function like working, eating, having relationships, having fun, making love, humans in urban systems require an operational space-time mode to achieve the best performance, as well as, according to Farina and Belgrano [16], organisms in ecosystems, for every function, require an operational space with ecological characteristics. Results are expected to be open to different approaches and interpretations and would concern different fields such as urban planning, sociology, anthropology, systems theory, evolutionary sciences and environmental sciences.

This study elaborates data in an aggregated (and anonymous) form. This research has neither aimed to spy on individual user behaviour nor to suggest any 'Big Brother' policy for human life control. It aims to use LBS to visualize behavioural configurations of the entire community as a whole through the formation of landscape-scale patterns and the visualization of patch dynamics.

\section{METHODOLOGY}

This study processed time series data (1-hour intervals) by cell-phone antennas located in a $100 \mathrm{~km}^{2}$ area $(10 \times 10 \mathrm{~km})$ in the metropolitan area of Milan - Italy - (Fig. 1). Cell-phone traffic data refer to a cell and are recorded by antennas, as each antenna transmits on a given set of canals, different from those used by other antennas closed to it, to avoid interferences. Generally, a cell can be assumed to be a circular area around an antenna, even if radio signal is not homogeneously distributed due to direction and physical obstacles, such as morphology and buildings. Information regarding the position and activity of mobile-phone antennas has allowed the study to calculate their variation of 


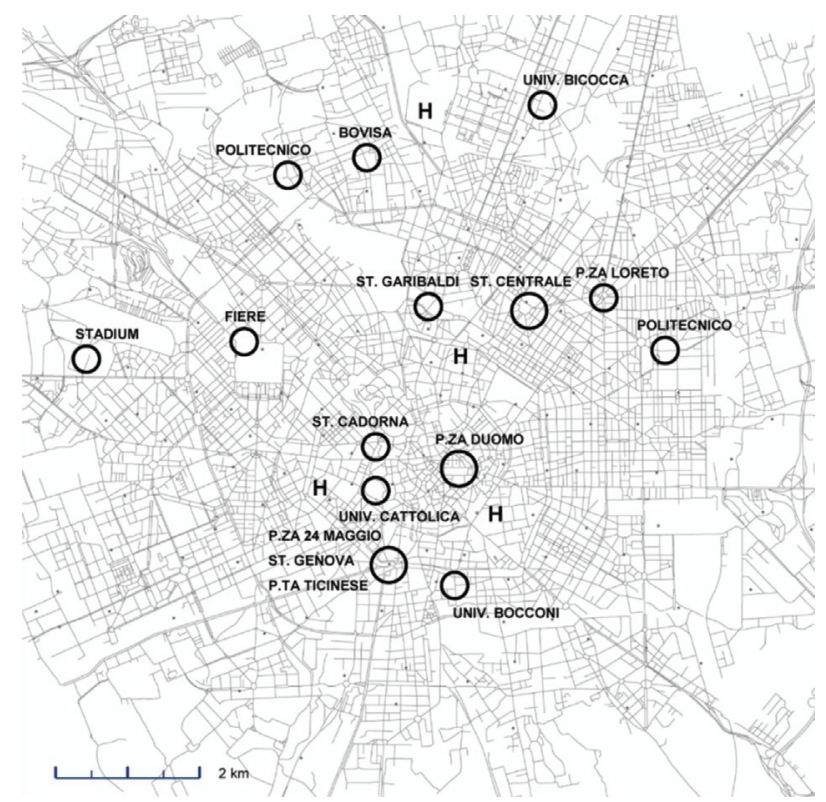

Figure 1: Map of the Milan metropolitan area: case study $10 \times 10 \mathrm{~km}$.

Table 1: Cells with coordinates and variables recorded per hour in unit erlang.

\begin{tabular}{lccccccc}
\hline Cell ID & $X$ (long) & $Y$ (lat) & Hour 1 & Hour 2 & $\ldots$ & Hour 23 & Hour 24 \\
\hline ID 001 & - & - & - & - & $\ldots$ & - & - \\
ID 002 & - & - & - & - & $\ldots$ & - & - \\
$\ldots$ & - & - & - & - & $\ldots$ & - & - \\
\hline
\end{tabular}

daily intensity (24 hours) and their evolution in time (position of antenna is fixed, data of traffic intensity is dynamic).

Data from mobile-phone antennas (intensity of cell-phone users activity) were transmitted to researchers by a national mobile telecommunications company in an aggregated (and anonymous) form. Data were calculated by combining position of cell-phone antennas, each of which has an ID number and geographical coordinates (232 antennas were located in the area under study) with cell-phone activity recorded by each antenna per each of 24 hours. This quantity is variable and given in the unit erlang, a standard unit of the telecommunications industry that combines the number and time of calls (e.g. 1 erlang $=1$ call $\times 60 \mathrm{~min}=2$ calls $\times 30 \mathrm{~min}=60$ calls $\times 1 \mathrm{~min}$ ).

In a data base, antennas are recorded with an ID number, geographical coordinates and a sequence of data in unit erlang for 24 columns, each of which corresponds to 1 hour, as shown in Table 1.

Data represent the quantity of information transmitted during 1 hour by each antenna. Considering a limited set of antennas located in the central area of Milan (circled on the map in Fig. 2), Fig. 3 shows erlangs plotted in diagrams. 


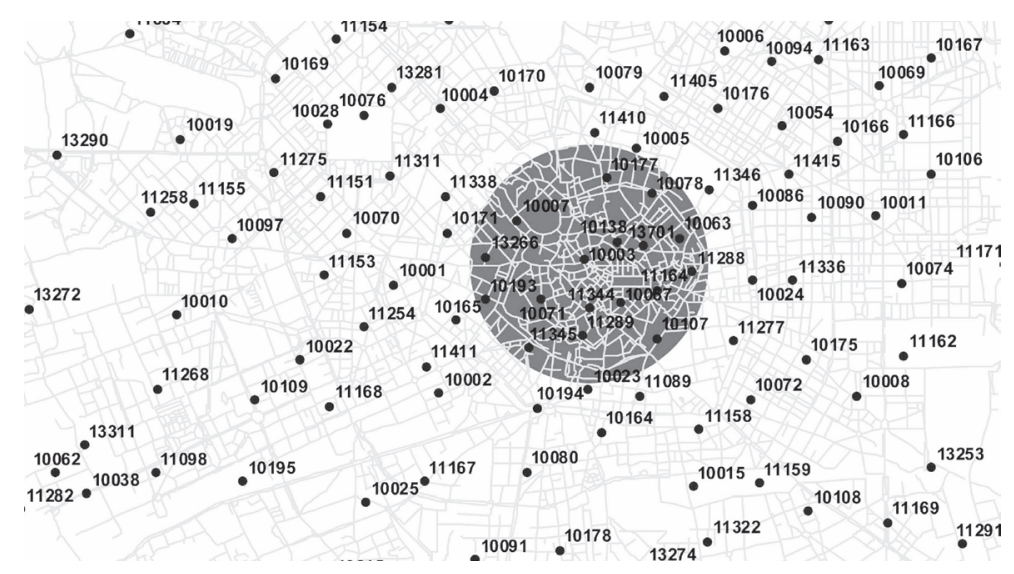

Figure 2: Location of cells to be plotted in diagrams.
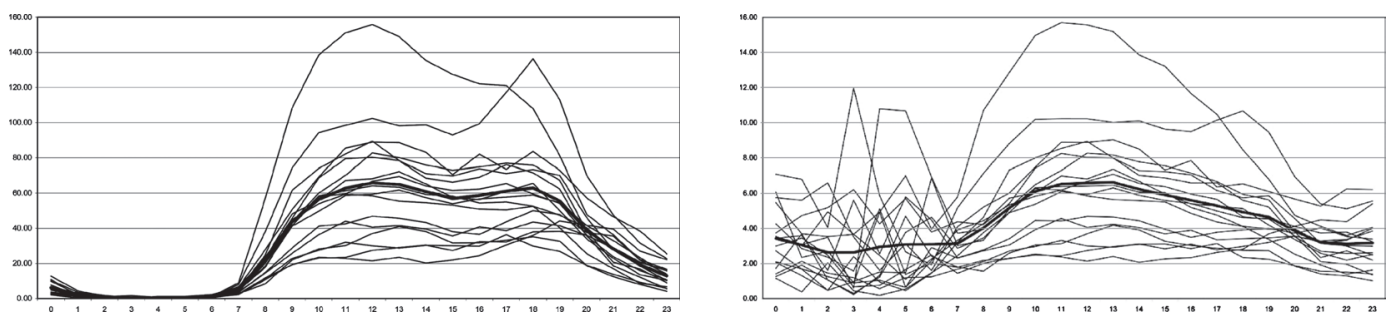

Figure 3: Curves of a set of cells located in the central area (circled in Fig. 2) in 24 hours given in unit erlang (left) and normalized values (right).

This highlights that social activity is high during the day and low during the night or, in other words, that the city switches on (or wakes up) in the morning and turns off at night. This obvious gap between night and day precludes the visualization of other phenomena, with smaller differences but necessary for our purposes.

\subsection{Normalization in space}

As erlang avoids any qualitative analysis, data were then transformed from erlang (absolute values) into relative values. Transformed data give the intensity of each antenna relative to the total activity of the entire area under study at a certain hour, and the gap between the highest and lowest values, such as day and night, was reduced.

Data were calculated according to the scheme in Table 2.

Proportioning is given by the following eqn (1):

$$
A_{j}=\sum_{i=1}^{n} a_{i j}, \quad a_{i j}=\frac{a_{i j}}{A_{j}},
$$

where $a_{i j}$ is the portion of traffic in one cell with respect to that in all the cells at a certain time and $a_{i j}$ is in unit erlang. In other words, this procedure is a 'normalization in space' with reference to the 
Table 2: Matrix of data in unit erlang: where $i=1, \ldots, n, n=232$ cells; $J=1, \ldots, m$, $m=24$ hours.

\begin{tabular}{lcccc}
\hline Cell ID & Hour 1 & Hour 2 & $\ldots$ & Hour $m$ \\
\hline ID 001 & $a_{11}$ & $a_{12}$ & $\ldots$ & $a_{1 m}$ \\
ID 002 & $a_{21}$ & - & $\ldots$ & - \\
$\ldots$ & $\ldots$ & $\ldots$ & $a_{i j}$ & - \\
ID $n$ & $a_{n 1}$ & - & $\ldots$ & $a_{n m}$ \\
$\sum$ & & & $A_{j}=\sum_{i=1}^{n} a_{i j}$ & \\
& & &
\end{tabular}

entire area under study per each one of the 24 hours. This answers a question: where is the highest intensity of activity at a given hour? This information is independent of the difference in intensity in different hours that was measured in unit erlang (Fig. 3, left).

The diagram of normalized data in Fig. 3 (right) refers to the antennas in the central area of Milan (circled in Fig. 2). It shows curves corresponding to each cell with a clear variation of activity during the 24 hours, as the problem of a wide gap between daily and nightly activity was over-crossed through proportioning values.

\subsection{Normalization based on cell size}

Antennas usually have a higher concentration in a central area with high population density than in areas with low density, such as suburbs. In this case study, there is a different concentration in central and peripheral areas. This character of network architecture creates some problems. For example, traffic data recorded by a peripheral antenna refer to a wider cell (antennas are less concentrated) than the same value recorded by an antenna in a city centre, where cells are smaller and close to one another. For this reason, intensity of activity should be normalized proportional to the size of the cell (smaller to more concentrated antennas). Figure 4 shows five areas with different concentrations of cell-phone antennas in the metropolitan area of Milan.

According to this classification, data were calculated through a coefficient corresponding to cell size, $\delta_{1_{-} 5}$. Equation (1) therefore changes into eqn (2):

$$
\bar{a}_{i j}=\frac{a_{i j}}{A_{j}} \times \delta_{1 \_5}
$$

\subsection{Mapping}

Once normalized data was provided, proportioned in space and adjusted on the basis of the classes of cell size, it was plotted on maps that visualize the intensity of activity within the metropolitan area of Milan through a grey scale (black for the highest intensity and white for the lowest). This procedure shows patterns of intensity of social activity in the entire area at a certain hour, while the information concerning difference of intensity between one hour and another was lost. For example, as the curves in Fig. 3 (right) present different values over the 24 hours, we can observe that, at 2 a.m., the 


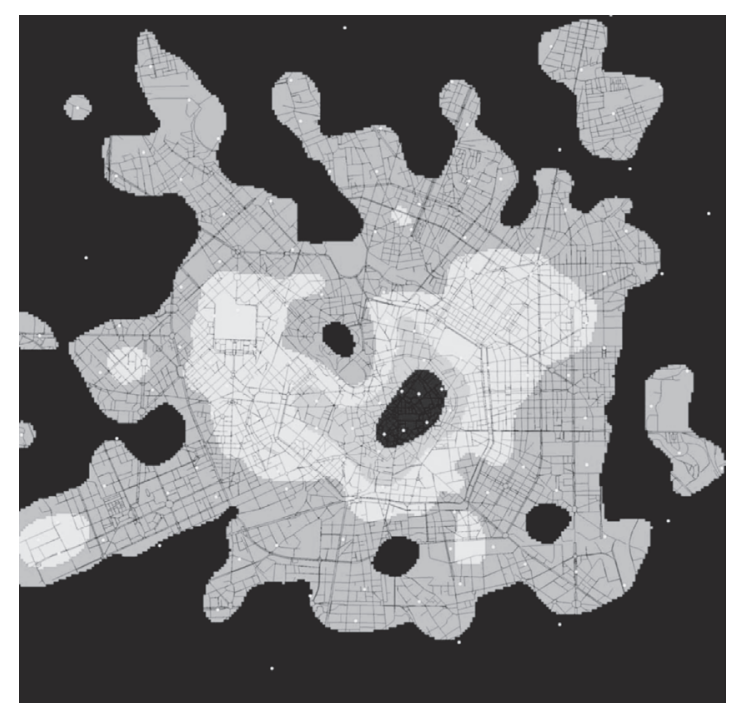

Figure 4: Areas with different concentrations of antenna corresponding to five categories based on cell size.

maximum value is about 6.5 and the minimum is about 0.5 , while, at 12 a.m., the maximum is 15.5 and the minimum is 2.0. Both maximum values and both minimum values have different intensities, at 2 a.m. and 12 a.m., but they were plotted on a map with the same colour (black for the maximum and white for the minimum).

Geo-statistical analysis allowed for the plotting of values on maps. This procedure is based on the interpolation of punctual data that gives computed values to unknown points. In this case study, a technique called inverse distance weighting was utilized, assuming that interpolation provides higher values to points closer to the centre of a given cell.

As the concentration of antennas was not homogeneous, we assumed a variable ray of cells and an interpolation was automatically computed by calculating intermediate values among sets of five given points.

Once plotted, some anomalies emerged, such as cells with values that were non-homogeneous and clearly discordant with other cells closed to them, probably due to the technical problem of transmission or configuration of the network. These values risked distorting the visualization of urban phenomena and were therefore deleted. After a deep analysis, 145 out of 232 cells were selected and finally plotted on maps. They are shown in Fig. 5.

\section{RESULTS AND DISCUSSION}

Data of mobile phone activity were plotted on a sequence of maps to visualize variations in intensity in the 24 hours of a working day. As we had assumed, intensity proportionally corresponds to social activity and, at least, to density of people. In Fig. 6, there is a sequence of frames corresponding to the 24 hours of Monday, 20 April 2004. When projected in a movie (a rapid sequence) these maps clearly provide a dynamic description of social behaviour in the metropolitan area.

Information of time-mode use of urban space was provided by analysing this map series. Some aspects of the general functioning of the whole urban-social system were highlighted, even 


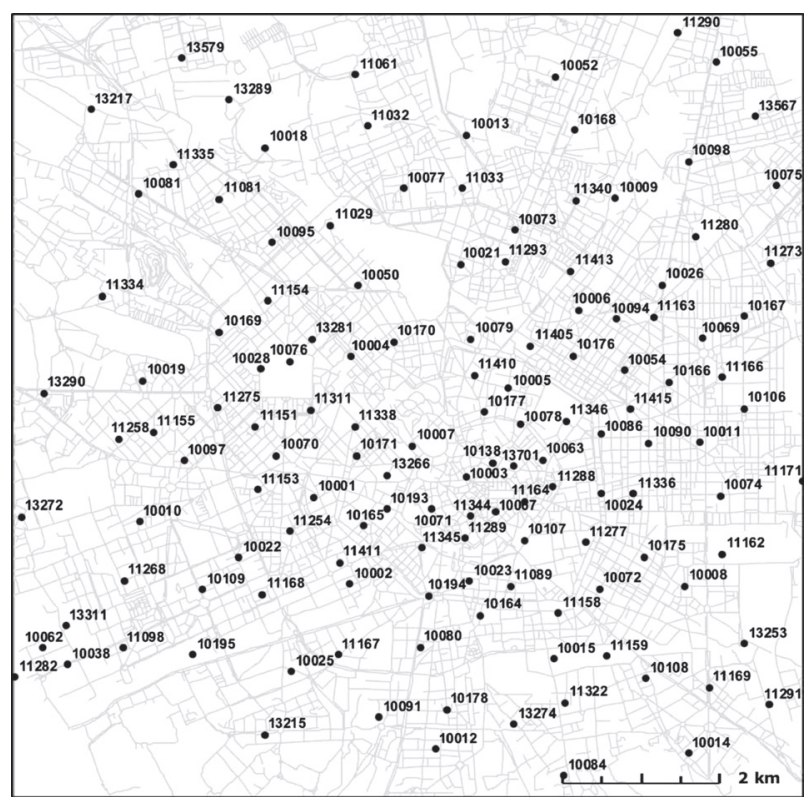

Figure 5: Map of the Milan metropolitan area: positioning antennas.

considering aggregated data. For example, considering the total daily activity (20 April), the 24 frames above were plotted on a unique synthetic map (Fig. 7) that shows a pattern of social activity in different areas of Milan with different land use intensity. In other words, this map answers the question: how intensively is urban space used? As a result, some areas were highlighted as intensively used, while some others appeared to be almost unused during a working day. The latter may be considered less important for urban dynamics, but, in some cases, they could be a valuable source for planning future strategic choices of urban development.

In Fig. 7, the highest intensity was shown by a shaded black pattern that corresponds to those areas in which most important urban functions are located such as: the Bicocca, Cattolica, Politecnico and Bocconi Universities; the San Giuseppe, Maggiore, Fatebenefratelli and Niguarda Ca' Granda Hospitals; the Centrale, Garibaldi, Cadorna, Genova Stations; working places in the centre and around Bovisa, Porta Nuova, Ticinese, Piazza 24 Maggio and Piazzale Loreto. Some other places have a lower intensity, especially peripheral areas and some places with special functions, such as the stadium and the Milano Fiere site, and even these are mostly assigned to low-density residential functions.

Classes based on time use of urban space were considered, as cells can have similarities. For example, cells with high activity during office hours (from 8 a.m. to 1 p.m. and from 3 p.m. to 5 p.m.), evening (from 8 p.m. to 2 a.m.), night (from 2 a.m. to 7 a.m.) and lunch-time (from 1 p.m. to 2 p.m.). These categories were computed in the database as shown in Table 3 and then plotted on maps.

Maps in Fig. 8 show a time-based land use according to the categories above. They show the areas with the highest intensity during office hours, evening, night and lunch time. This analysis answers the question: When is urban space used?

In Fig. 8a, circles correspond to high intensity during office hours. In Milan, these places are mostly located in the central area. The highest intensity corresponds to the area around the Centrale 

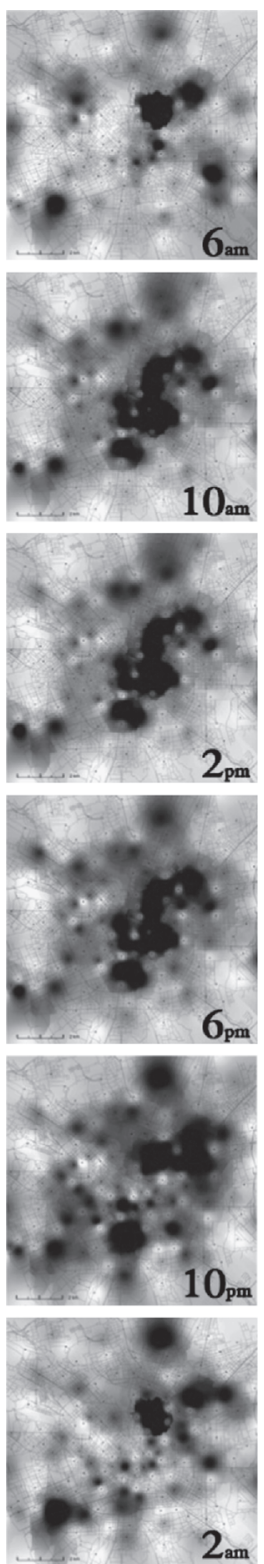
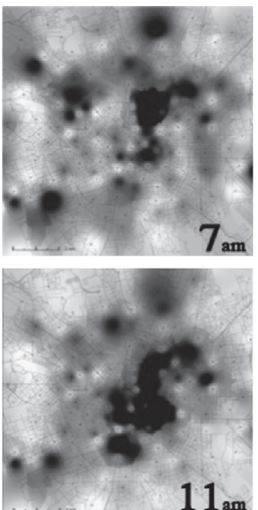

$11_{\mathrm{am}}$
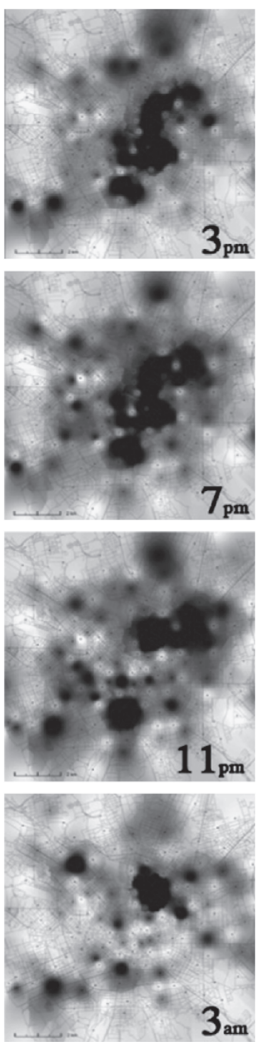
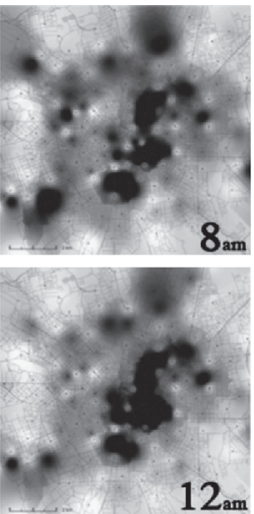

12 am
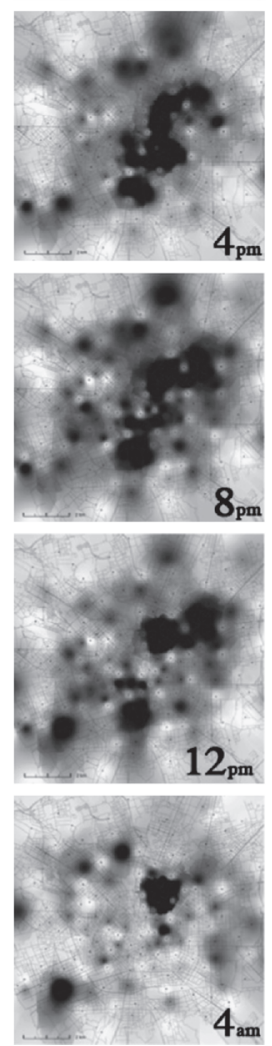
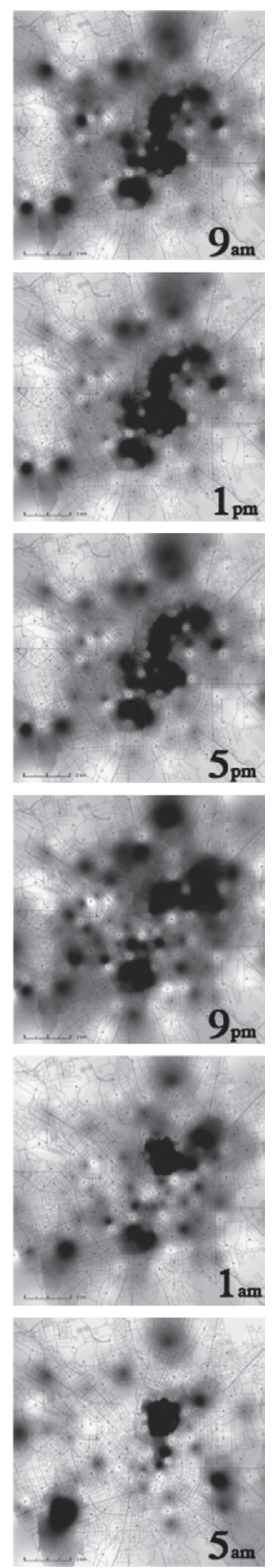

Figure 6: Sequence of maps with intensity of activity in the Milan metropolitan area: frames correspond to 24 hours of Monday, 20 April 2004. 


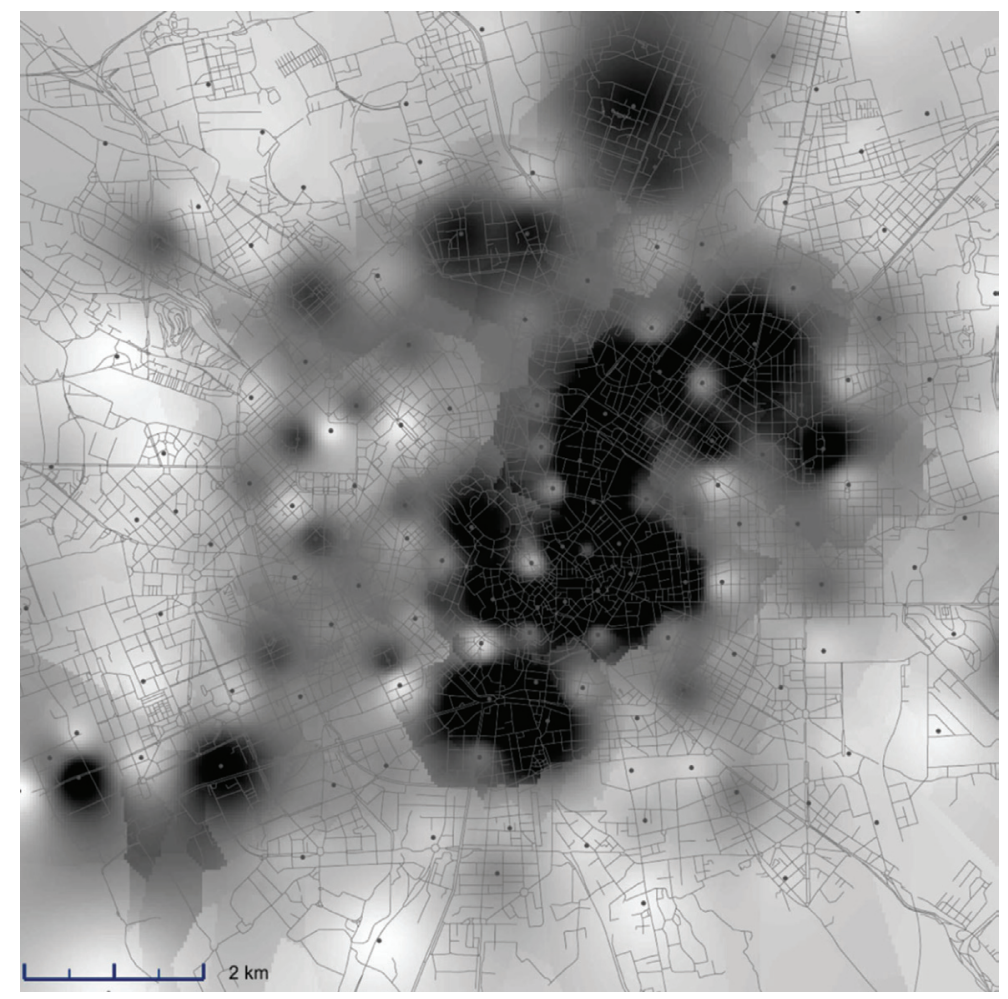

Figure 7: Synthetic map of urban zoning (land use) based on time use of urban space. Intensity goes from dark (high) to white (low). Recorded on Monday, 20 April 2004.

Table 3: In the column 'total $24 \mathrm{~h}$ ' intensity corresponds to: high (3), medium (2), low (1). In other columns, intensity is shown as follows: high (1), other (0).

\begin{tabular}{lccccccc}
\hline Cell ID & $X$ (long) & $Y$ (lat) & $\begin{array}{c}\text { Total } \\
24 \text { hours }\end{array}$ & $\begin{array}{c}\text { Office } \\
\text { hours }\end{array}$ & Evening & Night & $\begin{array}{c}\text { Lunch } \\
\text { time }\end{array}$ \\
\hline ID 001 & - & - & 3 & 0 & 1 & 0 & 0 \\
ID 002 & - & - & 1 & 0 & 1 & 1 & 0 \\
ID 003 & - & - & 2 & 1 & 0 & 0 & 1 \\
$\ldots$ & $\ldots$ & $\ldots$ & $\ldots$ & $\ldots$ & $\ldots$ & $\ldots$ & $\ldots$ \\
ID 145 & - & - & 1 & 0 & 1 & 1 & 0 \\
\hline
\end{tabular}

Station and the city centre. In particular, some places were highlighted, such as the Cattolica University, with the Cadorna Station, the Politecnico University, with Piazzale Loreto and the Bocconi University, with Piazza 24 Maggio. Figure $8 \mathrm{~b}$ refers to the evening, highlighting the Centrale, Garibaldi, Cadorna and Genova Stations, where commuters take trains after work, while circles in Piazzale Loreto and Corso Buenos Aires and that found in Navigli show places where people have an appetizer drink, or, 

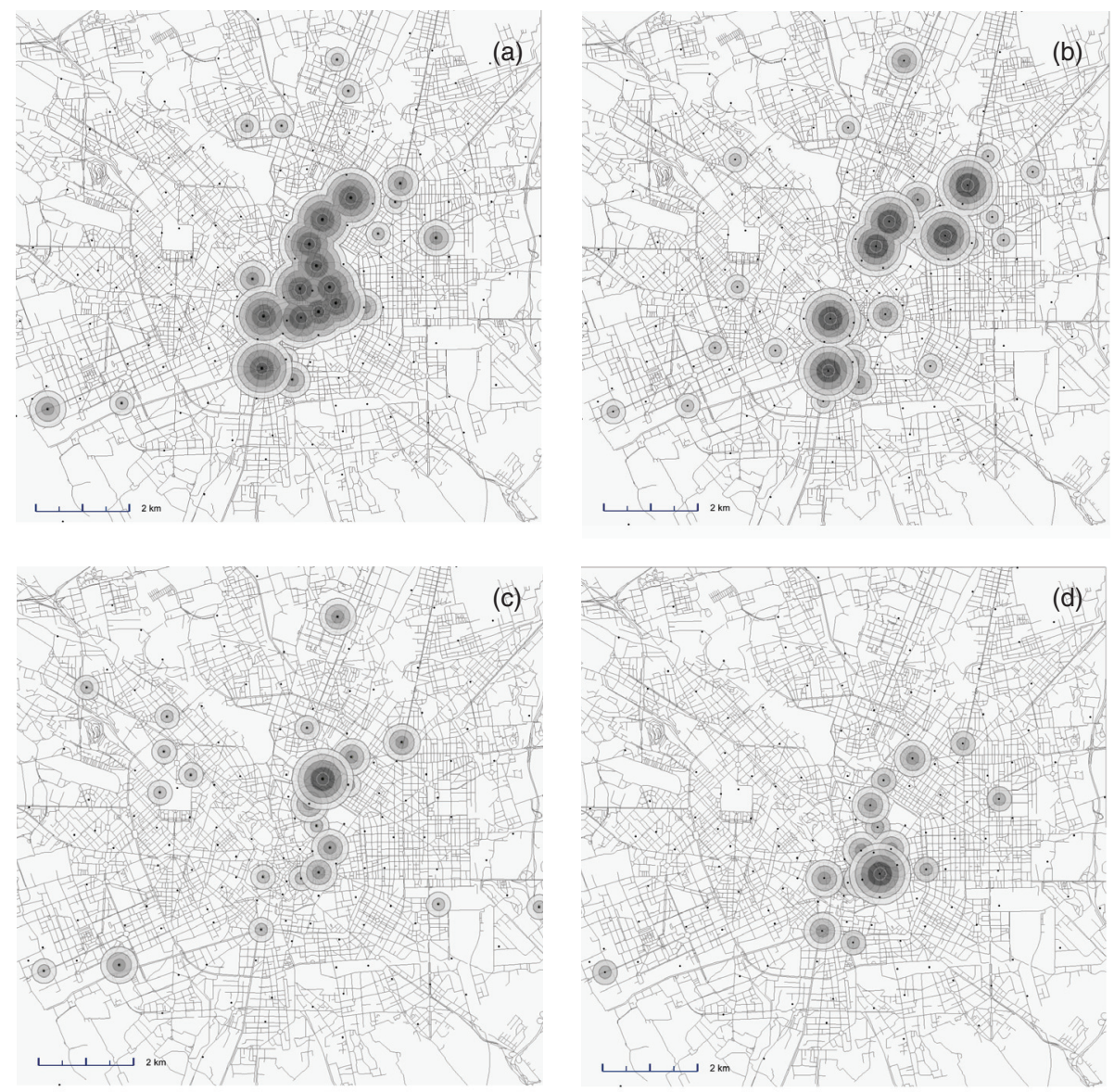

Figure 8: Areas with (a) high intensity during office hours (from 8 a.m. to 1 p.m. - from 3 p.m. to 5 p.m.); (b) high intensity during evening (from 8 p.m. to 2 a.m.); (c) high intensity during the night (from 2 a.m. to 7 a.m.); (d) high intensity during lunch time (from 1 p.m. to 2 p.m.). Recorded on Monday 20 April 2004.

in some cases, a traffic jam. Figure $8 \mathrm{c}$ shows high activity around the Centrale Station during the night. Figure 8d shows high intensity in the city centre during lunch time.

Intensity of activity was also visualized in a series of days in succession (from 19 April to 4 May 2004). Total daily values were plotted in order to visualize variations of intensity on different days and to investigate how different patterns can emerge during working days and weekends. These maps show activity with similar intensity on working days and very clear variations on Saturday and Sunday. Social life behaves in different ways according to different circumstances. In Fig. 9, maps of working days, Saturday and Sunday in the Milan metropolitan area were shown.

On the weekend, activity appears to be located mostly in peripheral areas with residential functions, while the city centre has a lower intensity than on working days. On Saturdays and Sundays, activity is more spread out, rather than highly concentrated in working places as on working days. On Sundays, the area around the stadium is very active, as 80,000 people attend the soccer match. 

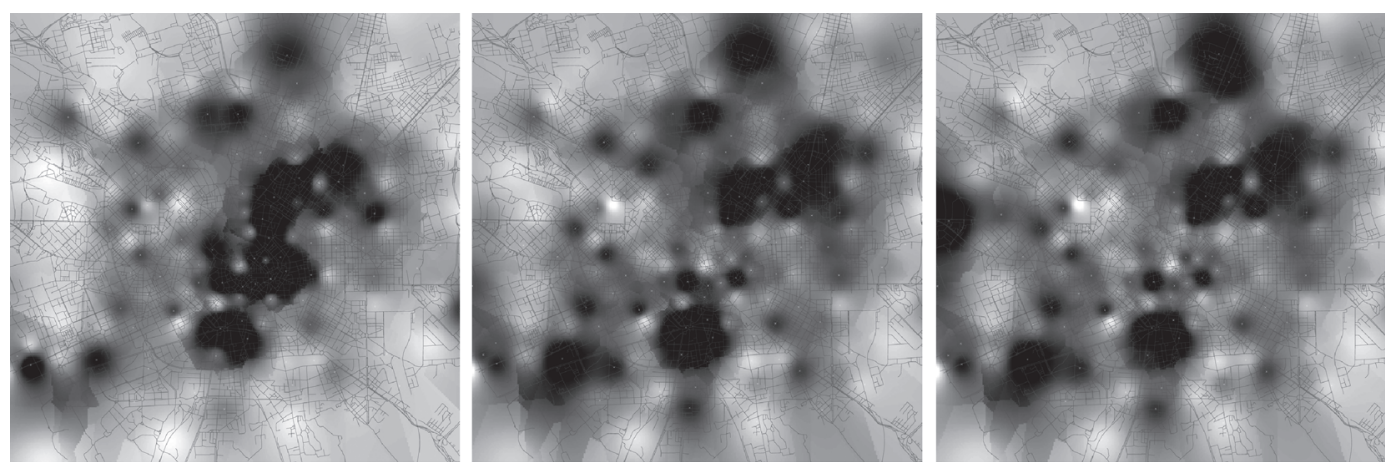

Figure 9: Maps with patterns of social activity related to an entire day. Comparing working days, Saturday and Sunday, different social behaviours were shown. Intensity goes from dark (high) to white (low). Recorded on Thursday, 29 April 2004 (left), Saturday, 1 May 2004 (middle) and Sunday, 2 May 2004 (right).

Finally, special events were observed in order to test this monitoring technique. Results provided clear evidence in some cases. In Fig. 10, there is a sequence on Sunday, 2 May 2004. On this day, there was an important soccer match at the stadium (Milan vs Roma -3 p.m. kick-off). The Milan team won the match and the 'Serie A' championship (5 p.m.). After the match, Milan supporters started their celebration around the stadium and moved to the central square, Piazza del Duomo (7 p.m.).

In Fig. 10, activity was plotted on a photo map of Milan in which lighted and shaded areas were shown relative to intensity (high intensity corresponds to light while low intensity corresponds to shade). Activity at the stadium starts around $10 \mathrm{a} . \mathrm{m}$. increases and is high at $1 \mathrm{p} . \mathrm{m}$. It suddenly decreases after 3 p.m. (kick-off time) because people do not use their cell phones during the match. It immediately becomes very high after the match at 5 p.m., and lights switch on the map all around the stadium (it looks like an explosion of happiness). Then people move to the city centre, in Piazza del Duomo, for the celebration (7 p.m.).

\section{CONCLUSION}

Cell-phone traffic data were studied for monitoring the intensity of people chatting and, indirectly, population density in real time. Patterns of social activity, with variable intensity, were observed to visualize time modes of urban space use. Questions to answer were: When and how long do people use urban space?

In particular, this study investigated urban-social dynamics in the Milan metropolitan area over 24 hours and on different days. Repetitive behaviours, for example in a sequence of working days, as well as the emergence of novelties, in the case of special events, were observed through patch dynamics. Areas with high and low intensity of activity were detected to investigate how intensive urban space was used in 24 hours and to compare behaviours on working days, Saturday and Sunday. As a result, mapping hotspots, a kind of functional zoning was presented on the basis of time of urban space use, rather than merely on functions.

More practically, this technique could be a tool for analysing urban dynamics, for instance, observing pattern configurations before, during and after an event like the construction of an urban infrastructure with a new function such as a new subway station or a new road that modifies mobility flows. 

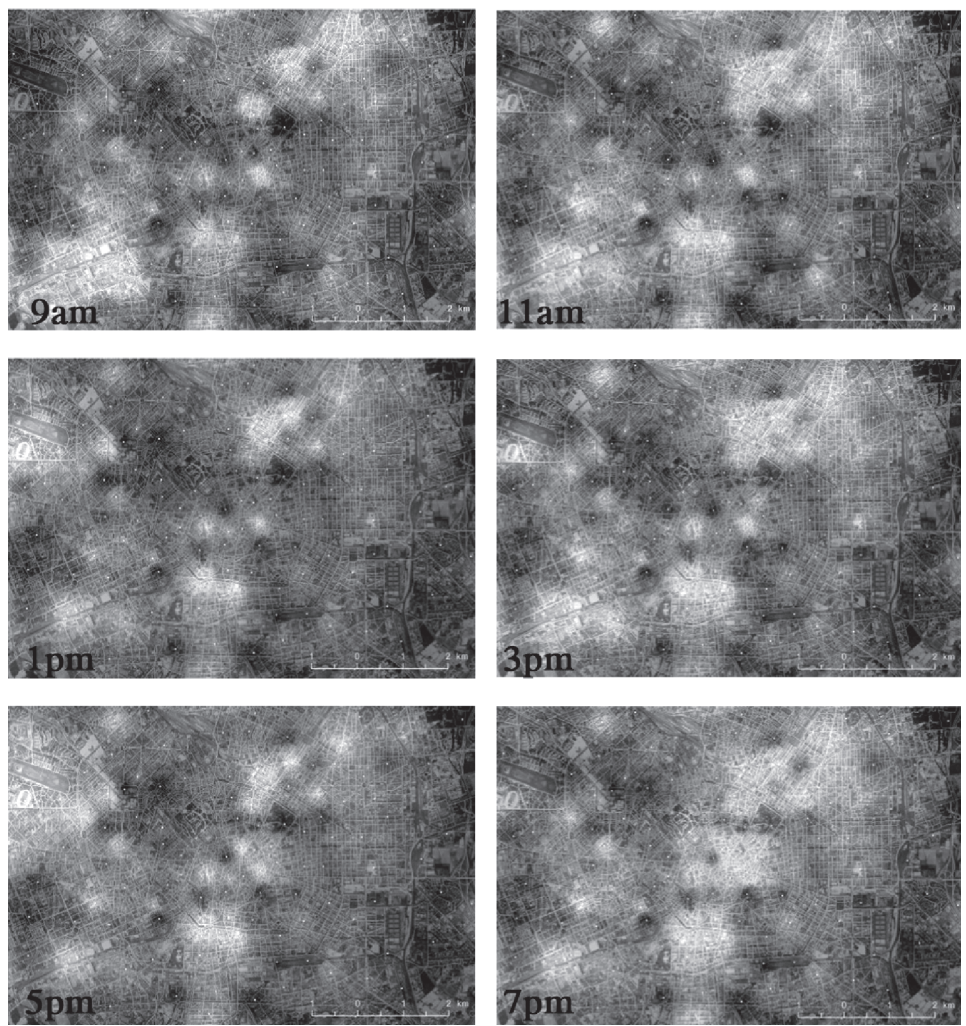

Figure 10: Sequence of maps with intensity of activity in the Milan metropolitan area: frames correspond to Sunday, 2 April 2004 when Milan won the 'Serie A' championship after a match at the stadium. Intensity was plotted on a photomap and goes from light (high) to shadow (low).

This would allow to rapidly verify the effects of certain actions, since feedback between communities and urban services can be elicited contributing to the complexity of urban-social systems and unpredicted outcomes may emerge. The visualization of patch dynamics can support planning practices and manage urban resilience. Considering this is potentially available in real time, it could work for simulating future scenarios and making choices. This is one of next objectives of this research.

Furthermore, processes that determine the distribution of people and intensity of social activity in the built-up environment were investigated through a holistic viewpoint and city life was shown as a whole, as patterns can be visible at the scale of the whole system, by virtue of the interactions among constitutive elements at the scale of individuals. According to Ulanowicz [17], in the field of systems ecology, organizational and developmental properties of ecosystems are taken as wholes, and these structural and dynamical properties are studied to describe and explain the formation of macro-level patterns in systems composed of many interacting micro-level constituents or components.

Collective behaviour with new properties, that elude the control and understanding of individuals, may emerge as an effect of variation in relations between the different components of a system (social, economic, technological, physical) [18]. The emergence of novelties and unexpected events can surface in a city's organization. Simple examples could be a traffic jam, a critical mass 
concentration (e.g. around a commercial centre on a Saturday evening) or even a low concentration (e.g. a city centre during warm summer afternoons) and a celebration for a special event (e.g. a soccer match or a concert). Variable patterns can show the effects of very localized road works on the organization of an entire neighbourhood. They can show how a new service, such as a coffee-shop with a very good cappuccino on the corner, can periodically change modes of functioning of a wider system. Cases like these can be observed through a cell-phone based monitoring technique to provide some evidence of complex behaviours in an urban system, with reference to the recent insights in organized complexity, which are closely related to the self-organizing and self-regulating capacities and to co-evolutionary processes in nature and in human societies [19].

The more complex and characterized by the interdependence of its parts (often highly specialized) a system is, the more likely it is that its effects, which may be due to local phenomena, are felt on a large scale $[20,21]$. This is greatly concerned with a holistic conception of multifunctional landscapes [22] applied to urban systems. In this vision, landscapes are concrete, space-time defined ordered whole human systems [23] in built-up environments. Their complex network interactions (between living organisms/people and their non-living physical context) cannot be comprehended merely by analysis, but only by synthesis within the context of the organization of the whole [22].

\section{REFERENCES}

[1] Adams, P.M., Ashwell, G.W.B. \& Baxter, R., Location-based services: an overview of the standards. BT Technology Journal, 21, pp. 34-43, 2003.

[2] Spinney, J.E., Mobile positioning and LBS applications. Geography, 88, pp. 256-265, 2003.

[3] Ratti, C., Williams, S., Frenchman, D. \& Pulselli, R.M., Mobile landscapes: using location data from cell phones for urban analysis. Environment \& Planning B: Planning and Design, 33(5), pp. 727-748, 2006.

[4] Ratti, C., 2005. Mobile landscape - Graz in real time. Proceedings of 3rd Symposium on LBS \& TeleCartography, Vienna University of Technology, 28-30 November 2005.

[5] Ahas, R. \& Mark, Ü., Location services: new challenges for planning and public administration? Futures, 37, pp. 547-561, 2005.

[6] Calabrese, F. \& Ratti, C., Real time Rome. Networks and Communication Studies, 20(3-4), pp. 247-258, 2006.

[7] Ahas, R., Aasa, A., Mark, Ü., Pae, T. \& Kull, A., Seasonal tourism spaces in Estonia: case study with mobile positioning data. Tourism Management, 28, pp. 898-910, 2007.

[8] Reades, J., Calabrese, F., Sevtsuk, A. \& Ratti, C., Cellular census: exploration in urban data collection. IEEE Pervasive Computing, 6(3), pp. 30-38, 2007.

[9] EITO, Report by the European Information Technology Observatory EITO. http://www.eito.com/ index-eito.html, 2004.

[10] Koolhaas, R., Boeri, S., Kwinter, S., Tazi, N. \& Obrist, H.U., Mutations, Actar, Art en Reve Centre d'Architecture: Bordeaux, 2000.

[11] Pickett, S.T.A., Burch Jr., W.R., Foresman, T.W., Grove, J.M. \& Rowntree, R., A conceptual framework for the study of human ecosystems. Urban Ecosystems, 1, pp. 185-199, 1997.

[12] Pickett, S.T.A., Cadenasso, M.L. \& Grove, J.M., Resilient cities: meaning, models, and metaphor for integrating the ecological, socio-economic, and planning realms. Landscape and Urban Planning, 69, pp. 369-384, 2004.

[13] Turner, M.G., Landscape ecology: the effect of pattern on process. Annual Review of Ecology and Systematics, 20, pp. 171-197, 1989.

[14] Turner, M., Gardner, G.R.H. \& O'Neill, R.V., Landscape Ecology in Theory and Practice: Pattern and Process, Springer: New York, 2001. 
[15] Jaros, M., Towards re-definition of space-ness in the post-mechanical age: methodological notes. Landscape and Urban Planning, 83, pp. 84-89, 2007.

[16] Farina, A. \& Belgrano, A., The eco-field hypothesis: toward a cognitive landscape. Landscape Ecology, 21, pp. 5-17, 2006.

[17] Ulanowicz, R.E., Growth and Development: Ecosystems Phenomenology, Springer-Verlag: New York, 1986.

[18] Pulselli, R.M., Pulselli, F.M. \& Marchettini, N., The conjunction of non-living and living in human systems: why do novelties emerge? International Journal of Ecodynamics, 2(4), pp. 245-249, 2007.

[19] Naveh, Z., What is holistic landscape ecology? A conceptual introduction. Landscape and Urban Planning, 50, pp. 7-26, 2000.

[20] Tiezzi, E., Steps Towards an Evolutionary Physics, WIT Press: Southampton, UK, 2006.

[21] Pulselli, R.M., Ratti, C. \& Tiezzi, E., City out of chaos: social patterns and organization in urban systems. International Journal of Ecodynamics, 1(2), pp. 126-135, 2006.

[22] Naveh, Z., Ten major premises for a holistic conception of multifunctional landscapes. Landscape and Urban Planning, 57, pp. 269-284, 2001.

[23] Naveh, Z., Landscape ecology as an emerging branch of human ecosystem science. Advances in Ecology Research, 12, pp. 189-237, 1982. 